Article

\title{
Influence of Ripening Stage and Cultivar on Physicochemical Properties and Antioxidant Compositions of Aronia Grown in South Korea
}

\author{
Haejo Yang ${ }^{1}$, Young-Jun Kim ${ }^{2, *}$ and Youngjae Shin ${ }^{3, *}$ \\ 1 Department of Environmental Horticulture, Dankook University, Cheonan, Chungnam 31116, Korea; \\ gowh1231@naver.com \\ 2 Department of Food Science and Technology, Seoul National University of Science and Technology, \\ Seoul 01811, Korea \\ 3 Department of Food Engineering, Dankook University, Cheonan, Chungnam 31116, Korea \\ * $\quad$ Correspondence: kimyj@seoultech.ac.kr (Y.-J.K.); ys234@dankook.ac.kr (Y.S.)
}

Received: 17 October 2019; Accepted: 19 November 2019; Published: 20 November 2019

\begin{abstract}
The present study investigated the fruits of aronia (Aronia melanocarpa) across different stages of maturity and analyzed their physicochemical properties, antioxidant compositions, and activities. The selected aronia cultivars ('Viking', 'McKenzie', and 'Kingstar K1' were categorized based on maturity into the immature stage (red tip), intermediary stage (red), and mature stage (dark purple). The key sugar components of aronia fruits were fructose, glucose, and sorbitol, while the main organic acid was found to be malic acid. The antioxidant content and activity of all three aronia cultivars showed significantly higher values for the red tip stage than the red or dark purple stages. However, the total anthocyanin content of aronia was the highest at the dark purple stage in three cultivars. The main polyphenols in aronia fruits were found to be catechol and chlorogenic acid, with a decreasing tendency as maturation progressed. As a result, the red tip stage of aronia fruits contains comparatively more abundant flavonoids, phenolic compounds and polyphenols than the dark purple stage, with higher antioxidant activity.
\end{abstract}

Keywords: aronia grown in Korea; antioxidant compounds; catechol; chlorogenic acid; anthocyanin; antioxidant activity

\section{Introduction}

In recent years, berries have received considerable attention due to their high content of flavonoids, anthocyanins, and polyphenols. Further, berries are known to have a very beneficial effect on human health [1]. Anthocyanin is a naturally occurring secondary metabolite in plants, and it is known to be effective in preventing obesity, diabetes, and cardiovascular disease and in improving cognitive function [2]. These effects are related to antioxidant activity, which has the same mechanism as that corresponding to free radical scavenging activity, inhibition of peroxidase, and vasodilation. The major substances showing such biological activity are phenolic compounds, including anthocyanins, flavonoids, tannin, organic acids and vitamins [3].

Aronia (genus Aronia) is a deciduous shrub and grows in the wild in the northern United States. It is classified into Aronia melanocarpa (Michx.) Ell., which is known as black chokeberry, Aronia arbutifolia (L.) Pers., which is known as red chokeberry, and Aronia prunifolia, which is a purple chokeberry bred by cross-fertilization of $A$. melanocarpa and A. arbutifolia [4]. A. melanocarpa has mainly been used as a raw material for natural pigments in the food and pharmaceutical industries. It is the most widely grown cultivar since juice, jam and wine production became available [5]. The most 
important commercial A. melanocarpa cultivars in Europe and the United States are 'Aron', 'Nero', 'Viking', 'Hugin' and 'Rubina'. The main polyphenol components of 'Viking' fruit are proanthocyanidin and anthocyanin; therefore, the 'Viking' fruit has been widely used as a natural raw material for food, pharmaceuticals, and cosmetics.

It has also been known to have significant antioxidant, anti-inflammatory and anti-cancer effects, in addition to being effective in blood glucose control [6]. Therefore, in this study, the typical domestic A. melanocarpa cultivars, 'Viking', 'McKenzie' and 'Kingstar K1' were selected and they were harvested at the red tip, red, and dark purple stages of fruit maturity. The objective of this study is to determine changes in the physicochemical properties, antioxidant profiles and activities of aronia and to investigate the effects of cultivar and maturity stage at harvest because none of the studies has considered these two factors simultaneously.

\section{Materials and Methods}

\subsection{Plant Materials}

The aronia samples were A. melanocarpa 'Viking', 'McKenzie', and 'Kingstar K1' grown in a farm in Cheongju, Chungcheongbuk-do, South Korea. The samples were collected from 30 bushes on each cultivar, depending on the maturity stage. There was a total of 27 samples since there were 3 cultivars $\times 3$ maturities $\times 3$ replicates. We collected $3 \mathrm{~kg}$ for each sample. The changes in physicochemical characteristics, antioxidant compound composition and antioxidant activity of the samples were analyzed according to maturity. Fruit maturity was classified into three stages according to the degree of fruit coloring: red tip, red, and dark purple. The fruit at these three stages was harvested in mid-June of 2017 (red tip), mid-July of 2017 (red), and in mid-August of 2017 (dark purple), respectively. The climatic condition data of mean temperature $\left({ }^{\circ} \mathrm{C}\right)$ and total precipitation $(\mathrm{mm})$ were collected from the Korea Meteorological Administration. The average temperature $\left({ }^{\circ} \mathrm{C}\right)$ and total precipitation $(\mathrm{mm})$ of each harvest month in 2017 were $23.4{ }^{\circ} \mathrm{C}$ and $17.5 \mathrm{~mm}, 27.1^{\circ} \mathrm{C}$ and $789.1 \mathrm{~mm}$, and $26.1^{\circ} \mathrm{C}$ and $225.2 \mathrm{~mm}$, respectively.

The harvested aronia fruits were immediately transferred to the laboratory, and the damaged fruits were removed. Then, the fruits were rapidly frozen with liquid nitrogen and then extracted for analysis of antioxidant compounds and antioxidant activities. The physicochemical qualities of the fruits, such as moisture content, color, firmness, $\mathrm{pH}$ and titratable acidity were analyzed on the day of the harvest. Photographs were also taken under the same conditions using a digital camera (EOS 550D, Canon, Tokyo, Japan) for visual comparison for color analysis.

\subsection{Chemical Reagents}

Ethanol, Folin-Ciocalteu's phenol reagent, 2,2-diphenyl-1-picrylhydrazyl (DPPH), 2,2-azino-bis (3-ethylbenzothiazoline-6-sulfonic acid) (ABTS), aluminum chloride hexahydrate, sodium nitrite, (+)-catechin, gallic acid monohydrate, sodium acetate anhydrous, potassium chloride, hydrochloric acid, sodium carbonate anhydrous, oxlalic acid, tartaric acid, malic acid, lactate, acetic acid, citric acid, succinic acid, fumaric acid, fructose, glucose, sucrose, maltose, lactose, sorbitol, gallic acid, protocatechuic acid, catechol, catechin, chlorogenic acid, epigallocatechin gallate, caffeic acid, epicatechin, syringic acid, 4-methycatechol, epicatechin gallate, p-coumaric acid, ferulic acid, and rutin were purchased from Sigma (St. Louis, MO, USA).

\subsection{Extraction for Measurement of Antioxidant Compounds and Activities}

To prepare the fruit extract, approximately $40 \mathrm{~g}$ of frozen aronia fruit was ground to a fine powder under liquid nitrogen by cold mortar and pestle and $30 \mathrm{~g}$ of the resultant powder was added to $300 \mathrm{~mL}$ of $80 \%$ ethanol, and then this mixture was homogenized in a commercial blender (HR-2171, Phillips, Seoul, Korea) three times for $3 \mathrm{~min}$ each time. The homogenate was centrifuged at $5230 \times g$ for $20 \mathrm{~min}$ using a centrifuge (Mega 21R, Hanil, Incheon, Korea). The supernatant was filtered using a Whatman 
\#2 filter paper and concentrated using a rotary evaporator (N-1000, Eyela, Tokyo, Japan). The samples were then brought to $30 \mathrm{~mL}$ with deionized water, expressed as $\mathrm{mg}$ of fruit on a fresh weight basis, divided into several aliquots, and kept frozen at $-20^{\circ} \mathrm{C}$ until analysis.

\subsection{Color Analysis}

The color change of the fruits was represented as $L^{*}$ value (lightness ranging from $0=$ black to $100=$ white), $\mathrm{a}^{*}$ value (redness), and $\mathrm{b}^{*}$ value (yellowness) using a colorimeter (Chroma meter CR-400, Minolta, Tokyo, Japan). The Chroma Meter was calibrated regularly using the white calibration plate $(Y=87.8, x=0.3156, y=0.3229)$. For each measurement, 30 fruits were measured three times, and the mean value was calculated. The readings were taken around the equatorial region of each fruit.

\subsection{Soluble Solid Content, Firmness, Titratable Acidity, pH and Moisture Content}

The firmness of the fruit was measured using a fruit hardness tester (FHM-1, Dementra Co., Ltd., Tokyo, Japan). The intact skin part of the fruit was penetrated using a $12 \Phi \times 10 \mathrm{~mm}$ cone probe, and the value was expressed in newtons $(\mathrm{N})$. The soluble solid content, titratable acidity, and $\mathrm{pH}$ were measured using a mixture of $10 \mathrm{~g}$ of fruit and $100 \mathrm{~mL}$ of deionized water that was homogenized with an Oster blender (Oster, Milwaukee, WI, USA). Soluble solid content was measured using a digital refractometer (PAL-1, Atago Co, Ltd., Tokyo, Japan). Titratable acidity was determined by mixing $2 \mathrm{~g}$ of the mixture and $200 \mathrm{~mL}$ of distilled water and performing a neutralization titration with $0.1 \mathrm{~N} \mathrm{NaOH}$ and 3-4 drops of $1 \%$ phenolphthalein solution. The $\mathrm{pH}$ was measured using a $\mathrm{pH}$ meter (Starter300, Ohaus Co, Ltd., Parsippany, NJ, USA). To measure the water content of the fruit, $20 \mathrm{~g}$ of fruit was weighed and stored in an incubator (IB-05G, Jeio Tech Co., Ltd., Seoul, Korea) set to $60^{\circ} \mathrm{C}$ until there was no change in weight. Then, fruits were weighed again, and weight loss percentage was obtained.

\subsection{Organic Acid Compositions}

Organic acid composition profiling was performed as described by Kim and Shin [7], with some modifications. An Agilent 1100 series (Agilent Technologies, Wilmington, DE, USA) with a diode array detector (DAD) was used for the individual organic acid analysis. The extract was diluted in ten-fold distilled water and the samples were filtered through a $0.45 \mu \mathrm{m}$ syringe. A prevail organic acid column $\left(250 \times 4.6 \mathrm{~mm}\right.$ i.d., $5 \mu \mathrm{m}$, Hichrom Ltd., Reading, UK) was used at $25^{\circ} \mathrm{C}$, and a DAD was positioned at $210 \mathrm{~nm}$. The HPLC (High-Performance Liquid Chromatography) mobile phase was 25 $\mathrm{mM} \mathrm{KH}_{2} \mathrm{PO}_{4}$ adjusted to $\mathrm{pH} 2.1$ using $\mathrm{H}_{3} \mathrm{PO}_{4}$ with a $1.0 \mathrm{~mL} / \mathrm{min}$ flow rate, and the injection volume was $3 \mu \mathrm{L}$. For the calibration curves, the three different points $(4,20,100 \mathrm{mg} / 100 \mathrm{~g}$ for oxlate, tartarate, malate, lactate, acetate, citrate, succinate, and fumarate) were prepared with standard solutions, and the unit for the results was expressed in $\mathrm{mg} / 100 \mathrm{~g}$ of fresh weight (FW).

\subsection{Sugar Composition}

The sugar composition profiling was performed as described by Kim and Shin [7]. Aronia sample extracts were diluted ten-fold in distilled water and then the samples were filtered through a 0.45 $\mu \mathrm{m}$ syringe filter. HPLC analyses were carried out using an UltiMate 3000 HPLC system (Thermo Fisher Scientific, Waltham, MA, USA) with a Refractomax 520 refractive index (RI) detector (ERC Inc, Saitama, Japan). A carbohydrate high-performance column $(250 \times 4.6 \mathrm{~mm}$ i.d., $4 \mu \mathrm{m}$, Waters Corp., Milford, MA, USA) was utilized at $30^{\circ} \mathrm{C}$ for individual sugar identification. The mobile phase was $79 \%$ acetonitrile in distilled water with a $1.0 \mathrm{~mL} / \mathrm{min}$ flow rate, and the injection volume was 10 $\mu \mathrm{L}$. Standard calibration curves were prepared with 200,500 and $1000 \mathrm{mg} / 100 \mathrm{~g}$ of fructose, glucose, sucrose, maltose, lactose and sorbitol as reference materials. The determination was performed three times for each sample, and the results were shown as $\mathrm{mg} / 100 \mathrm{~g}$ of FW. 


\subsection{Total Anthocyanin Analysis}

The total anthocyanin content of fruit extracts was measured by the $\mathrm{pH}$ differential method $[8,9]$. The extracts were mixed with $0.025 \mathrm{M}$ potassium chloride buffer ( $\mathrm{pH} 1.0$ ) and $0.4 \mathrm{M}$ sodium acetate buffer ( $\mathrm{pH} 4.5)$, and absorbance was measured at 510 and $700 \mathrm{~nm}$ using a spectrophotometer (Optizen POP, Mecasys, Daejeon, Korea). The total anthocyanin content was calculated using the following equation and expressed as mg cyanidin 3-glucoside equivalents (CGE)/100 g FW.

$$
\text { Total anthocyanin content }(\mathrm{mg} \text { CGE } / 100 \mathrm{~g} \mathrm{FW})=\frac{(\mathrm{A} \times \mathrm{MW} \times \mathrm{D} \times 1000)}{\varepsilon}
$$

where MW (molecular weight of cyanidin 3-glucoside) $=449.2 ; \mathrm{D}=$ dilution factor; $\varepsilon$ (molar extinction coefficient of cyanidin 3-glucoside) $=26,900$.

$$
\text { A }(\text { absorbance value })=\left((\mathrm{A} 510 \mathrm{~nm}-\mathrm{A} 700 \mathrm{~nm})_{\mathrm{pH} 1.0}-(\mathrm{A} 510 \mathrm{~nm}-\mathrm{A} 700 \mathrm{~nm})_{\mathrm{pH} 4.5}\right)
$$

\subsection{Total Flavonoid Analysis}

The total flavonoid content of fruit extracts was measured by the colorimetric assay method $[8,9]$. In total, $0.3 \mathrm{~mL}$ of $5 \% \mathrm{NaNO}_{2}$ was added to a $1 \mathrm{~mL}$ aliquot of the diluted sample mixed with deionized water, thoroughly mixed, and allowed to react for $5 \mathrm{~min}$. Then, $0.3 \mathrm{~mL}$ of $10 \% \mathrm{AlCl}_{3}$ was added, thoroughly mixed, and allowed to react for $6 \mathrm{~min}$. Lastly, $2 \mathrm{~mL}$ of $1 \mathrm{~N} \mathrm{NaOH}$ and $2.4 \mathrm{~mL}$ of distilled water were added to adjust the total volume to $10 \mathrm{~mL}$. Then, the absorbance was measured at a wavelength of $510 \mathrm{~nm}$ using a spectrophotometer. The standard curve was measured using catechin, and the total flavonoid content was expressed as mg catechin equivalents (CE)/100 g FW.

\subsection{Total Phenolic Analysis}

Total phenolic content of fruit extracts was measured by the Folin-Ciocalteu colorimetric method [8,9]. $0.2 \mathrm{~mL}$ of the Folin-Ciocalteu reagent was added to a $0.2 \mathrm{~mL}$ aliquot of the diluted sample mixed with deionized water, thoroughly mixed, and allowed to stand at room temperature for $6 \mathrm{~min}$. Then, $2 \mathrm{~mL}$ of $7 \% \mathrm{NaCO}_{3}$ was added and allowed to stand for $90 \mathrm{~min}$ at room temperature in a dark place, and absorbance was measured at $750 \mathrm{~nm}$ wavelength using a spectrophotometer. The standard curve was measured using gallic acid, and the total phenolic compound content was expressed as mg gallic acid equivalents (GAE)/100 FW.

\subsection{Polyphenol Analysis}

The polyphenol content of fruit extracts was analyzed using a modified method by Chen [10]. The extract was diluted twenty times with diluted solution $\left(\mathrm{KH}_{2} \mathrm{PO}_{4}: \mathrm{MeOH}: \mathrm{D} . \mathrm{W}=2: 3: 15\right)$, and the diluted solution was filtered with a $0.45 \mu \mathrm{m}$ syringe filter. The filtered samples were analyzed using HPLC (Thermo Fisher UltiMate 3000, Thermo Scientific, Bremen, Germany), and Eclipse XDBC-18 column $\left(150 \times 4.6 \mathrm{~mm}, 5 \mu \mathrm{m}\right.$, Agilent Technologies, Wilmington, DE, USA) at $40^{\circ} \mathrm{C}$. Acetic acid $(3 \%)$ was used as the HPLC mobile phase, and the detector was set to a wavelength of $280 \mathrm{~nm}$ and a flow rate of 1.0 $\mathrm{mL} / \mathrm{min}$, where $10 \mu \mathrm{L}$ of the samples were injected and analyzed. The standard calibration curve was measured using the following as standards: gallic acid, protocatechuic acid, catechol, catechin, chlorogenic acid, epigallocatechin gallate, caffeic acid, epicatechin, syringic acid, 4-methycatechol, epicatechin gallate, p-coumaric acid, ferulic acid, and rutin. The content was expressed as mg/100 g FW.

\subsection{DPPH Radical Scavenging Activity Analysis}

The DPPH radical scavenging activity was measured using a modification of the method described by Brand-Williams [11]. The DPPH solution was prepared by dissolving the $0.00789 \mathrm{~g}$ of powdered DPPH into $200 \mathrm{~mL}$ of methanol. The test solution containing $50 \mu \mathrm{L}$ of the diluted solution mixed with deionized water and $2950 \mu \mathrm{L}$ of $0.2 \mathrm{mM}$ DPPH solution was allowed to react for $30 \mathrm{~min}$, and the 
absorbance was measured at a wavelength of $517 \mathrm{~nm}$ using a spectrophotometer. The antioxidant activity of the extract was expressed as mg vitamin C equivalents (VCE)/100 $\mathrm{g}$ FW.

\subsection{ABTS Radical Scavenging Activity Analysis}

The ABTS radical scavenging activity of the extracted sample was measured using ABTS radicals [12]. The test solution containing $20 \mu \mathrm{L}$ of the diluted solution mixed with deionized water and $980 \mu \mathrm{L}$ of the ABTS reaction solution was reacted at $37^{\circ} \mathrm{C}$ for $10 \mathrm{~min}$, and the absorbance was measured at a wavelength of $734 \mathrm{~nm}$ using a spectrophotometer. The antioxidant activity of the extract was expressed as $\mathrm{mg}$ vitamin C equivalents (VCE)/100 g FW.

\subsection{Statistical Analysis}

For statistical analysis, one-way analysis of variance (ANOVA) was performed using SPSS 20 program (SPSS Inc., Chicago, IL, USA), and Duncan's multiple range test was used for the significance of each average value $(p<0.05)$. The correlation between the mean values of each parameter was expressed using Pearson's correlation coefficient. The data were expressed as the mean \pm standard deviation from triplicate determination.

\section{Results and Discussion}

\subsection{Color}

The color and appearance at harvest day depending on the maturity of aronia are shown in Figure 1, and Hunter $\mathrm{L}$, $\mathrm{a}$, and $\mathrm{b}$ color of $A$. melanocarpa fruits at different maturity stages are shown in Table 1. In all three cultivars, lightness (L value) decreased as the fruit color darkened during the ripening process from red tip stage to dark purple stage. Redness (a value) increased gradually from red tip stage to red stage in all three cultivars but decreased at dark purple stage when the fruit color darkened. Yellowness ( $b$ value) showed a tendency to decrease from a positive value to a negative value in all three cultivars as maturation progressed.

\begin{tabular}{|c|c|c|c|}
\hline \multirow{2}{*}{ Stage } & \multicolumn{3}{|c|}{ Cultivar } \\
\hline & Viking & McKenzie & Kingstar K1 \\
\hline Red tip & & & \\
\hline Red & & & \\
\hline $\begin{array}{l}\text { Dark } \\
\text { purple }\end{array}$ & & & \\
\hline
\end{tabular}

Figure 1. Color and appearance of Aronia melanocarpa fruits at different maturity stages. 
Table 1. Hunter L, a, b color of Aronia melanocarpa fruits at different maturity stages.

\begin{tabular}{llccc}
\hline Cultivar & Maturity Stage & $\mathbf{L}^{*}$ & $\mathbf{a}^{*}$ & $\mathbf{b}^{*}$ \\
\hline Viking & Red tip & $43.53 \pm 1.99^{\mathrm{b}}$ & $-7.74 \pm 1.36^{\mathrm{e}}$ & $12.17 \pm 2.14^{\mathrm{a}}$ \\
Viking & Red & $27.23 \pm 1.35^{\mathrm{e}}$ & $9.86 \pm 0.31^{\mathrm{a}}$ & $2.33 \pm 1.20^{\mathrm{d}}$ \\
Viking & Dark purple & $23.81 \pm 1.03^{\mathrm{g}}$ & $1.02 \pm 0.31^{\mathrm{c}}$ & $-1.84 \pm 0.15^{\mathrm{e}}$ \\
\hline McKenzie & Red tip & $44.63 \pm 2.66^{\mathrm{a}}$ & $-6.34 \pm 1.46^{\mathrm{d}}$ & $9.83 \pm 2.46^{\mathrm{b}}$ \\
McKenzie & Red & $28.75 \pm 1.57^{\mathrm{d}}$ & $10.18 \pm 1.85^{\mathrm{a}}$ & $3.54 \pm 1.34^{\mathrm{c}}$ \\
McKenzie & Dark purple & $25.28 \pm 0.74^{\mathrm{f}}$ & $1.00 \pm 0.36^{\mathrm{c}}$ & $-2.42 \pm 0.36^{\mathrm{e}}$ \\
\hline Kingstar K1 & Red tip & $42.65 \pm 1.17^{\mathrm{c}}$ & $-6.77 \pm 0.84^{\mathrm{d}}$ & $9.90 \pm 1.14^{\mathrm{b}}$ \\
Kingstar K1 & Red & $28.22 \pm 1.56^{\mathrm{d}}$ & $9.14 \pm 1.51^{\mathrm{b}}$ & $2.72 \pm 1.44^{\mathrm{d}}$ \\
Kingstar K1 & Dark purple & $22.26 \pm 0.72^{\mathrm{h}}$ & $1.19 \pm 0.44^{\mathrm{c}}$ & $-1.78 \pm 0.15^{\mathrm{e}}$ \\
\hline
\end{tabular}

Color measurement was expressed as lightness $\left(\mathrm{L}^{*}\right)$, redness $\left(\mathrm{a}^{*}\right)$, and yellowness $\left(\mathrm{b}^{*}\right)$. Results are the mean values \pm standard deviation from three measurements $(n=3)$; means in the same column with superscript with different letters $(\mathrm{a}, \mathrm{b}, \mathrm{c}, \mathrm{d}, \mathrm{e}, \mathrm{f}, \mathrm{g}$, and $\mathrm{h}$ ) are significantly different at $p<0.05$.

\subsection{Soluble Solid Content, Firmness, Titratable Acidity, $p H$, and Moisture Content}

The soluble solid content, firmness, titratable acidity, $\mathrm{pH}$, and sugar/acid ratio of aronia fruit are shown in Table 2. The soluble solid content significantly decreased from the red tip stage to the red stage and slightly increased from the red stage to the dark purple stage without any significant difference. Kaack and Kuhn [13] also reported that soluble solid content increased during the ripening process of black chokeberry. Firmness decreased with maturation in all three cultivars, and water content increased as maturation progressed. Taheri [14] demonstrated that differences in water content of fruits generally did not affect the polyphenol content and water content increased with maturation stage. The titratable acidity was $1.26 \%-1.30 \%$, the differences between cultivars and between maturity stages were negligible, and the highest $\mathrm{pH}$ was shown at the dark purple stage. Many studies on the quality analysis of aronia fruit reveal that the soluble solid content of aronia fruit is in the range of $12 \%$ to $20 \%$, and the titratable acidity is $0.7 \%-1.4 \%$ [15]. The results of this study showed that the sugar-acid ratios of the aronia fruit at the red and dark purple stages were not significantly different in three cultivars. In general, during the ripening process of fruits, the soluble solid content and sugar content are increased while titratable acidity and organic acid content are decreased [16]. However, physicochemical properties of the fruit are affected by various factors such as climatic conditions, soil composition, and maturity during harvest, and these factors are known to have a significant influence on fruit quality [17]. 
Table 2. Soluble solid contents (SSC), firmness, titratable acidities, $\mathrm{pH}$ and moisture content of Aronia melanocarpa fruits at different maturity stages.

\begin{tabular}{|c|c|c|c|c|c|c|c|c|}
\hline Cultivar & Maturity Stage & SSC $\left({ }^{\circ}\right.$ Brix $)$ & $\begin{array}{c}\text { Firmness (N/12 } \\
\text { mmØ) }\end{array}$ & $\begin{array}{c}\text { Titratable } \\
\text { Acidity (\%) }\end{array}$ & $\begin{array}{l}\text { Malic Acid } \\
(\mathrm{mg} / 100 \mathrm{~g})\end{array}$ & $\mathrm{pH}$ & SSC/TA Ratio & $\begin{array}{c}\text { Moisture } \\
\text { Content (\%) }\end{array}$ \\
\hline Viking & Red tip & $16.00 \pm 1.00^{b}$ & $3.95 \pm 0.34^{b}$ & $1.26 \pm 0.04^{b}$ & $448.62 \pm 6.50^{\mathrm{e}}$ & $3.52 \pm 0.06^{\mathrm{de}}$ & $12.72 \pm 0.87^{b}$ & $36.92 \pm 1.03^{d}$ \\
\hline Viking & Red & $12.33 \pm 0.58^{\mathrm{d}}$ & $2.05 \pm 0.21^{\mathrm{d}}$ & $1.30 \pm 0.01^{\mathrm{a}}$ & $658.29 \pm 31.30^{c}$ & $3.47 \pm 0.03^{\mathrm{e}}$ & $9.48 \pm 0.50^{\mathrm{d}}$ & $41.08 \pm 0.82^{c}$ \\
\hline Viking & Dark purple & $13.66 \pm 1.53^{\mathrm{cd}}$ & $0.99 \pm 0.23^{f}$ & $1.29 \pm 0.01^{a}$ & $827.78 \pm 42.63^{a}$ & $3.68 \pm 0.06^{c}$ & $10.57 \pm 1.23^{\mathrm{cd}}$ & $54.87 \pm 1.14^{\mathrm{a}}$ \\
\hline McKenzie & Red tip & $20.33 \pm 1.53^{a}$ & $4.04 \pm 0.18^{\mathrm{ab}}$ & $1.28 \pm 0.01^{\mathrm{ab}}$ & $434.15 \pm 16.78^{\mathrm{e}}$ & $3.79 \pm 0.02^{b}$ & $15.94 \pm 1.29^{a}$ & $38.58 \pm 1.28^{\mathrm{cd}}$ \\
\hline McKenzie & Red & $13.00 \pm 1.00 \mathrm{~cd}$ & $2.26 \pm 0.25^{c}$ & $1.29 \pm 0.01^{\mathrm{a}}$ & $669.78 \pm 22.02^{c}$ & $3.58 \pm 0.09^{d}$ & $10.09 \pm 0.78^{\mathrm{cd}}$ & $39.21 \pm 0.87 \mathrm{~cd}$ \\
\hline McKenzie & Dark purple & $14.67 \pm 0.58^{b c}$ & $1.15 \pm 0.20^{\mathrm{e}}$ & $1.28 \pm 0.01^{\mathrm{ab}}$ & $815.00 \pm 21.42^{\mathrm{a}}$ & $4.01 \pm 0.02^{\mathrm{a}}$ & $11.50 \pm 0.49 \mathrm{bc}$ & $46.64 \pm 1.70^{b}$ \\
\hline Kingstar K1 & Red tip & $20.67 \pm 1.53^{a}$ & $4.09 \pm 0.26^{\mathrm{a}}$ & $1.29 \pm 0.01^{\mathrm{ab}}$ & $448.73 \pm 16.77^{e}$ & $3.79 \pm 0.02^{b}$ & $16.04 \pm 1.20^{\mathrm{a}}$ & $40.06 \pm 0.69^{c}$ \\
\hline Kingstar K1 & Red & $13.00 \pm 1.00^{\mathrm{cd}}$ & $2.34 \pm 0.27^{c}$ & $1.29 \pm 0.01^{\mathrm{a}}$ & $578.43 \pm 29.32^{d}$ & $3.55 \pm 0.03 \mathrm{de}$ & $10.06 \pm 0.88^{\mathrm{cd}}$ & $38.44 \pm 2.17^{\mathrm{cd}}$ \\
\hline Kingstar K1 & Dark purple & $14.00 \pm 1.00 \mathrm{bcd}$ & $0.88 \pm 0.15^{f}$ & $1.28 \pm 0.01^{a b}$ & $758.33 \pm 36.45^{b}$ & $3.81 \pm 0.06^{b}$ & $10.90 \pm 0.78^{\mathrm{cd}}$ & $45.92 \pm 2.69^{b}$ \\
\hline
\end{tabular}

Results are the mean values \pm standard deviation from three measurements $(n=3)$; means in the same column with superscript with different letters $(a, b, c, d$, e, and f) are significantly different at $p<0.05$. SSC/TA ratio is calculated by SSC $\left({ }^{\circ}\right.$ Brix $) /$ titratable acidity $(\%)$ 


\subsection{Quantification of Individual Organic Acids}

Organic acids, sugars and volatile compounds, are known to contribute greatly to the taste and flavor of fruits [18]. Table 2 shows the results of measuring organic acid content of aronia fruit depending on maturity. The malic acid content of three cultivars increased significantly as the fruit became more mature. In comparison, between cultivars at each maturity stage, 'Viking' and 'McKenzie' showed similar malic acid content. However, the malic acid content of 'Kingstar K1' at the red and dark purple stage was significantly lower than that of other cultivars. Mikulic-Petkovsek et al. [19] reported that the major organic acids of berries were citric acid and malic acid. In this study, malic acid was found to be main organic acid, and other organic acids (oxlalic acid, tartaric acid, lactate, acetic acid, citric acid, succinic acid, fumaric acid) were not detected (below the limit of quantification (LOQ)). Therefore, malic acid was dominant at the dark purple stage where the fruit was completely ripe, which is consistent with the report that malic acid was the main organic acid of black chokeberry [15].

\subsection{Quantification of Individual Sugars}

Table 3 shows the sugar content of aronia fruit according to maturity. The contents of fructose, glucose, and sorbitol were significantly increased as ripening progressed. It was found that the sorbitol content was higher than fructose and glucose in each cultivar at all stages. Mikulic-Petkovsek et al. [19] showed that the sugar contents of aronia were glucose $3.54 \mathrm{~g} / 100 \mathrm{~g}$, fructose $2.82 \mathrm{~g} / 100 \mathrm{~g}$, sucrose $0.412 \mathrm{~g} / 100 \mathrm{~g}$, and sorbitol $4.62 \mathrm{~g} / 100 \mathrm{~g}$, but the bitter taste of ripened chokeberry was stronger than sweet taste because of its high content of polyphenol. Sorbitol was found to be the major sugar component of aronia fruit.

\subsection{Total Anthocyanin Content}

The total anthocyanin content of aronia fruit according to cultivar and maturity was the highest at the dark purple stage in three cultivars-224.62 mg/100 g FW in 'Viking'; $226.33 \mathrm{mg} / 100 \mathrm{~g}$ FW in 'McKenzie'; and $185.84 \mathrm{mg} / 100 \mathrm{~g} \mathrm{FW}$ in 'Kingstar K1' $(p<0.05)$-and was significantly higher than that at the red tip and red stages. The content was significantly higher in 'Viking' and 'McKenzie' than in 'Kingstar K1' (Figure 2A). In this study, the anthocyanin content of aronia fruit tended to increase with maturation. Siriwoharn [20] also reported a similar result that the total anthocyanin of blackberry 'Marion' increased from $74 \mathrm{mg} / 100 \mathrm{~g}$ FW in the unripe fruit to $317 \mathrm{mg} / 100 \mathrm{~g}$ FW in the ripe fruit, as maturation progressed and the total anthocyanin of 'Evergreen' also increased from $69.9 \mathrm{mg} / 100 \mathrm{~g}$ FW to $164 \mathrm{mg} / 100 \mathrm{~g} \mathrm{FW}$. According to Wang and Lin [21] on analysis of anthocyanin content according to green, pink, and ripe stage of berries, blackberry showed $0.9,9.1$, and $152.8 \mathrm{mg} / 100 \mathrm{~g}$, respectively; black raspberry showed $1.7,22.8$, and $197.2 \mathrm{mg} / 100 \mathrm{~g}$, respectively; red raspberry showed 1.0, 7.2, and $68.0 \mathrm{mg} / 100 \mathrm{~g}$, respectively; strawberry showed $0.3,5.5$, and $31.9 \mathrm{mg} / 100$ $\mathrm{g}$, respectively. Thus, the anthocyanin content increased with maturation progress in all berries. The anthocyanin content of berries was higher in the order of black chokeberry, black currant, blackberry, and raspberry [22]. 
Table 3. Individual sugar contents of Aronia melanocarpa fruits at different maturity stages.

\begin{tabular}{|c|c|c|c|c|c|}
\hline Cultivar & Maturity Stage & Fructose $(\mathrm{mg} / 100 \mathrm{~g}$ FW) & Glucose (mg/100 g FW) & Sorbitol (mg/100 g FW) & Total Sum (mg/100 g FW) \\
\hline Viking & Red tip & $113.51 \pm 33.48^{f}$ & $272.83 \pm 16.64^{f}$ & $1343.97 \pm 45.38^{\mathrm{e}}$ & 1730.31 \\
\hline Viking & Red & $841.90 \pm 85.80^{\mathrm{e}}$ & $972.32 \pm 76.02 \mathrm{e}$ & $1962.84 \pm 66.08^{\mathrm{d}}$ & 3777.05 \\
\hline Viking & Dark purple & $2103.11 \pm 194.48^{b}$ & $2366.75 \pm 250.94^{b}$ & $3882.51 \pm 536.95^{b}$ & 8352.37 \\
\hline McKenzie & Red tip & $17.63 \pm 11.53^{f}$ & $191.35 \pm 8.13^{f}$ & $1333.54 \pm 37.89^{\mathrm{e}}$ & 1542.51 \\
\hline McKenzie & Red & $1065.64 \pm 108.32^{d}$ & $1145.51 \pm 105.51^{\mathrm{e}}$ & $2518.72 \pm 323.36^{c}$ & 4729.86 \\
\hline McKenzie & Dark purple & $2477.12 \pm 74.65^{\mathrm{a}}$ & $2677.70 \pm 119.95^{\mathrm{a}}$ & $4831.56 \pm 129.08^{a}$ & 9986.37 \\
\hline Kingstar K1 & Red tip & $10.51 \pm 14.92^{\mathrm{f}}$ & $232.09 \pm 21.57^{f}$ & $1432.02 \pm 18.61^{\mathrm{e}}$ & 1674.62 \\
\hline Kingstar K1 & Red & $1252.83 \pm 108.20^{c}$ & $1405.74 \pm 95.03^{d}$ & $2747.56 \pm 210.53^{c}$ & 5406.13 \\
\hline Kingstar K1 & Dark purple & $1961.00 \pm 110.10^{b}$ & $2080.48 \pm 121.71^{\mathrm{c}}$ & $3593.35 \pm 173.51^{b}$ & 7634.84 \\
\hline
\end{tabular}

Results are the mean values \pm standard deviation from three measurements $(n=3)$; means in the same column with superscript with different letters (a, b, $\mathrm{c}, \mathrm{d}, \mathrm{e}$, and $\mathrm{f})$ are significantly different at $p<0.05$. FW: fresh weight. FW: Fresh weight. 

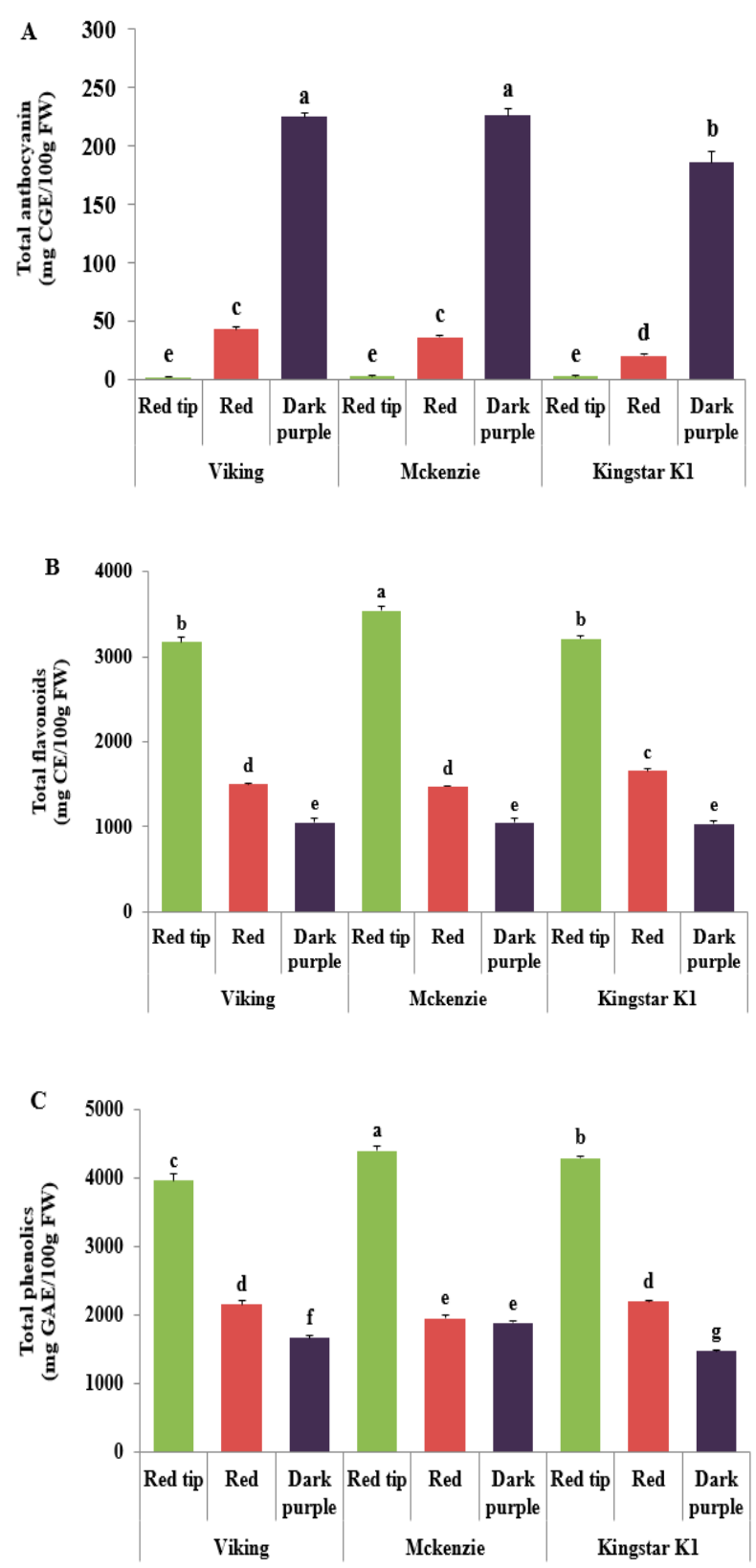

Figure 2. Total anthocyanin, total flavonoids and total phenolics contents of Aronia melanocarpa fruits at different maturity stages: (A) Total anthocyanin; (B) Total flavonoids; (C) Total phenolics. Vertical bars indicate standard deviation. Different letters are significant differences by Duncan's multiple range test $(p<0.05)$.

\subsection{Total Flavonoid Content}

The total flavonoid content of aronia fruit was highest at the red tip stage in three cultivars: $3175.52 \mathrm{mg} / 100 \mathrm{~g}$ FW in 'Viking'; $3544.7 \mathrm{mg} / 100 \mathrm{~g}$ FW in 'McKenzie'; and $3212.50 \mathrm{mg} / 100 \mathrm{~g}$ FW in 'Kingstar K1'. Thus, the flavonoid content at the red tip stage was significantly higher than that at the red stage and dark purple stage $(p<0.05)$ (Figure 2B). In particular, the total flavonoid content of 'McKenzie' at the red tip stage was significantly higher than that of 'Viking' and 'Kingstar K1' $(p<0.05)$. At the red stage, the total flavonoid content of 'Kingstar $\mathrm{K} 1$ ' was significantly higher than that of 'Viking' and 'McKenzie'. However, at the dark purple stage, there was no significant difference between the three cultivars. Therefore, the flavonoid content of aronia fruit decreased significantly as the ripening process progressed. Wang's [23] study on the change of flavonoid content in red raspberry 
according to maturity reported that the content of quercetin and kaempferol decreased significantly during ripening.

\subsection{Total Phenolics Content}

The total phenolic content of aronia fruit was highest at the red tip stage in three cultivars: $3955.28 \mathrm{mg} / 100 \mathrm{~g}$ FW in 'Viking'; $4393.50 \mathrm{mg} / 100 \mathrm{~g}$ FW in 'McKenzie'; and 4284.55 mg/100 g FW in 'Kingstar K1'. Thus, the total phenolic content at the red tip stage was significantly higher than that at the red and dark purple stage $(p<0.05)$ (Figure 2C). In the comparison between cultivars according to maturity, the phenolic content was higher at the red tip stage in the order of 'McKenzie', 'Kingstar $\mathrm{K} 1$ ', and 'Viking' $(p<0.05)$. At the red stage, 'Viking' and 'Kingstar $\mathrm{K} 1$ ' showed significantly higher phenolic contents than 'McKenzie' $(p<0.05)$, but the phenolic content was significantly higher at the dark purple stage in the order of 'McKenzie', 'Viking', and 'Kingstar K1' $(p<0.05)$. These results suggest that the total phenolic content of aronia decreased during the ripening process, which was a similar pattern to that of the flavonoid content.

Previous studies have shown that the anthocyanin content of blackberry increased significantly during ripening, but ellagitannin, flavonol, and ellagic acid content decreased significantly during the ripening process [24]. Black chokeberry is known to be a rich source of phenolic compounds, and polyphenol content was reported to be significantly higher in chokeberry $(690.2 \mathrm{mg} / 100 \mathrm{~g})$ than in red raspberry $(177.5 \mathrm{mg} / 100 \mathrm{~g})$ and blackberry $(289.3 \mathrm{mg} / 100 \mathrm{~g})$ [22,25]. In addition, the higher content of phenol compounds in unripe fruits than that in ripe fruits results from a large amount of phenylpropanoid substances contained in unripe fruits.

\subsection{Polyphenol Content}

The polyphenol content of $80 \%$ ethanol extract of aronia fruit was measured. As a result, major polyphenols were found to be catechol and chlorogenic acid (Table 4), and other polyphenol compounds (gallic acid, protocatechuic acid, catechin, epigallocatechin gallate, caffeic acid, epicatechin, syringic acid, 4-methycatechol, epicatechin gallate, p-coumaric acid, ferulic acid, and rutin) were not detected (below the LOQ). The catechol content of each cultivar at the red tip, red, and dark purple stage was $256.11,134.18$, and $95.05 \mathrm{mg} / 100 \mathrm{~g}$, respectively, in 'Viking'; 399.01, 118.02, and $81.80 \mathrm{mg} / 100$ $\mathrm{g}$, respectively, in 'McKenzie'; and 289.03, 118.33, and $70.69 \mathrm{mg} / 100 \mathrm{~g}$, respectively, in 'Kingstar $\mathrm{KI}^{\prime}$. Thus, the catechol content was the highest at the unripe stage and decreased significantly as maturation progressed. The chlorogenic acid content at the red tip, red, and dark purple stage was 120.82, 72.31, and $64.69 \mathrm{mg} / 100 \mathrm{~g}$, respectively, in 'Viking'; 176.67, 68.75, and $56.72 \mathrm{mg} / 100 \mathrm{~g}$, respectively, in 'McKenzie'; and 132.58, 72.87, and $49.76 \mathrm{mg} / 100 \mathrm{~g}$, respectively, in 'Kingstar KI'. Thus, the chlorogenic acid content showed a similar pattern to the catechol content. Sidor and Gramza-Michałowska [26] reported that Chokeberries mostly contain chlorogenic and neochlorogenic acids. Other phenolic acids are cryptochlorogenic acid, p-coumaric acid and its derivatives, caffeic acid and its derivatives, protocatechuic, vanillic, ferulic, salicylic, syringic, 4-hydroxybenzoic and ellagic acids. According to Taheri [14], approximately $78 \%$ of the hydroxycinnamic acid content of aronia was chlorogenic acid, and all aronia cultivars contained chlorogenic acid at approximately 3.11-13.5 mg/g DW. Määttä-Riihinen [27] reported that the hydroxycinnamic acid content of chokeberry was detected at $0.892 \mathrm{mg} / \mathrm{g} \mathrm{FW}$, which is similar to the result of this study. Wang and Lin [21] reported that phenolic content in berries was affected by maturity stage at harvest, genetic differences, environmental conditions at harvest, post-harvest storage conditions and processing. According to Zheng and Wang's [28] study on oxygen radical absorbance capacity of phenols in blueberry, cranberry, chokeberry and lingonberry, berries contained different contents of polyphenol depending on cultivar and genotype, and these polyphenols have high antioxidant activity. They also reported that higher polyphenol content leads to a higher antioxidant activity, which varies depending on the structure and composition of berries. In this study, the chlorogenic acid content in the unripe aronia was abundant, and chlorogenic acid, ferulic acid, caffeic acid, and p-coumaric acid are known to have high antibacterial 
activity [29]. Therefore, the results of this study suggest that the unripe aronia fruit containing the highest chlorogenic acid is useful in various food manufacturing fields.

Table 4. Polyphenol contents of Aronia melanocarpa fruits at different maturity stages.

\begin{tabular}{llccc}
\hline Cultivar & Maturity Stage & $\begin{array}{c}\text { Catechol } \\
(\mathbf{m g} / \mathbf{1 0 0} \mathbf{g} \text { FW })\end{array}$ & $\begin{array}{c}\text { Chlorogenic Acid } \\
(\mathbf{m g} / \mathbf{1 0 0} \mathbf{g} \text { FW })\end{array}$ & $\begin{array}{c}\text { Total Sum } \\
(\mathbf{m g} / \mathbf{1 0 0} \text { g FW) }\end{array}$ \\
\hline Viking & Red tip & $256.11 \pm 19.27^{\mathrm{c}}$ & $120.82 \pm 7.91^{\mathrm{b}}$ & 376.92 \\
Viking & Red & $134.18 \pm 6.48^{\mathrm{d}}$ & $72.31 \pm 4.81^{\mathrm{c}}$ & 206.49 \\
Viking & Dark purple & $95.05 \pm 6.93^{\mathrm{ef}}$ & $64.69 \pm 3.09^{\mathrm{cd}}$ & 159.74 \\
\hline McKenzie & Red tip & $399.01 \pm 22.22^{\mathrm{a}}$ & $176.62 \pm 15.57^{\mathrm{a}}$ & 575.63 \\
McKenzie & Red & $118.02 \pm 1.87^{\mathrm{de}}$ & $68.75 \pm 1.59^{\mathrm{cd}}$ & 186.78 \\
McKenzie & Dark purple & $81.80 \pm 3.50^{\mathrm{fg}}$ & $56.72 \pm 3.83^{\mathrm{de}}$ & 138.53 \\
\hline Kingstar K1 & Red tip & $289.03 \pm 10.88^{\mathrm{b}}$ & $132.58 \pm 5.39^{\mathrm{b}}$ & 421.61 \\
Kingstar K1 & Red & $118.33 \pm 1.59^{\mathrm{de}}$ & $72.87 \pm 2.81^{\mathrm{c}}$ & 191.20 \\
Kingstar K1 & Dark purple & $70.69 \pm 0.27^{\mathrm{g}}$ & $49.76 \pm 0.95^{\mathrm{e}}$ & 120.45 \\
\hline
\end{tabular}

Results are the mean values \pm standard deviation from three measurements $(n=3)$; means in the same column with superscript with different letters (a, b, c, d, e, f, and g) are significantly different at $p<0.05$.

\subsection{DPPH Radical Scavenging Activity}

The DPPH radical scavenging activity of aronia fruits was highest at the red tip stage in all three cultivars: $4141.44 \mathrm{mg} / 100 \mathrm{~g}$ FW in 'Viking'; $4565.28 \mathrm{mg} / 100 \mathrm{~g}$ FW in 'McKenzie'; and 4313.23 $\mathrm{mg} / 100 \mathrm{~g}$ FW in 'Kingstar K1'. Thus, the DPPH radical scavenging activity was significantly higher at the red tip stage than at the red and dark purple stages $(p<0.05)$ (Figure 3A). In the comparison between cultivars according to maturity, the DPPH radical scavenging activity was significantly higher at the red tip stage in the order of 'McKenzie', 'Kingstar K1', and 'Viking' $(p<0.05)$, and it was significantly higher at the red stage in the order of 'Kingstar K1', 'Viking', and 'McKenzie' $(p<0.05)$. At the dark purple stage, the DPPH radical scavenging activity was significantly higher in 'Viking' than in 'McKenzie' and 'Kingstar K1'. In this study, the changes in DPPH radical scavenging activity according to maturity showed a pattern similar to the changes in the total phenolic content and total flavonoid content. Benvenuti et al. [22] studied the DPPH radical scavenging activity of blackberry, blackcurrant, chokeberry, raspberry. They indicated a relatively high potential of chokeberries and selected blackcurrant varieties.

\subsection{ABTS Radical Scavenging Activity Analysis}

The ABTS radical scavenging activity of aronia fruit was highest at the red tip stage in all three cultivars: 5976.86 mg/100 g FW in 'Viking'; 6107.57 mg/100 g FW in 'McKenzie'; 6090.15 mg/100 g FW in 'Kingstar K1'. Thus, the ABTS radical scavenging activity at the red tip stage was significantly higher than that at the red and dark purple stage $(p<0.05)$ (Figure 3B). At the red stage, the ABTS radical scavenging activity was significantly higher in 'Viking' and 'Kingstar K1' than in 'McKenzie', and at the dark purple stage, there was no significant difference among the three cultivars. According to Wang and Lin's [21] study, blackberry, raspberry and strawberry, which were harvested at green stage, showed higher antioxidant activity than those at pink and ripe stage, similar to the results of this study. Tarko et al. [30] also reported that chokeberry fruit components were the most active scavengers of the ABTS radical cation among chokeberries, apples, plums, pears, bananas and melons. 

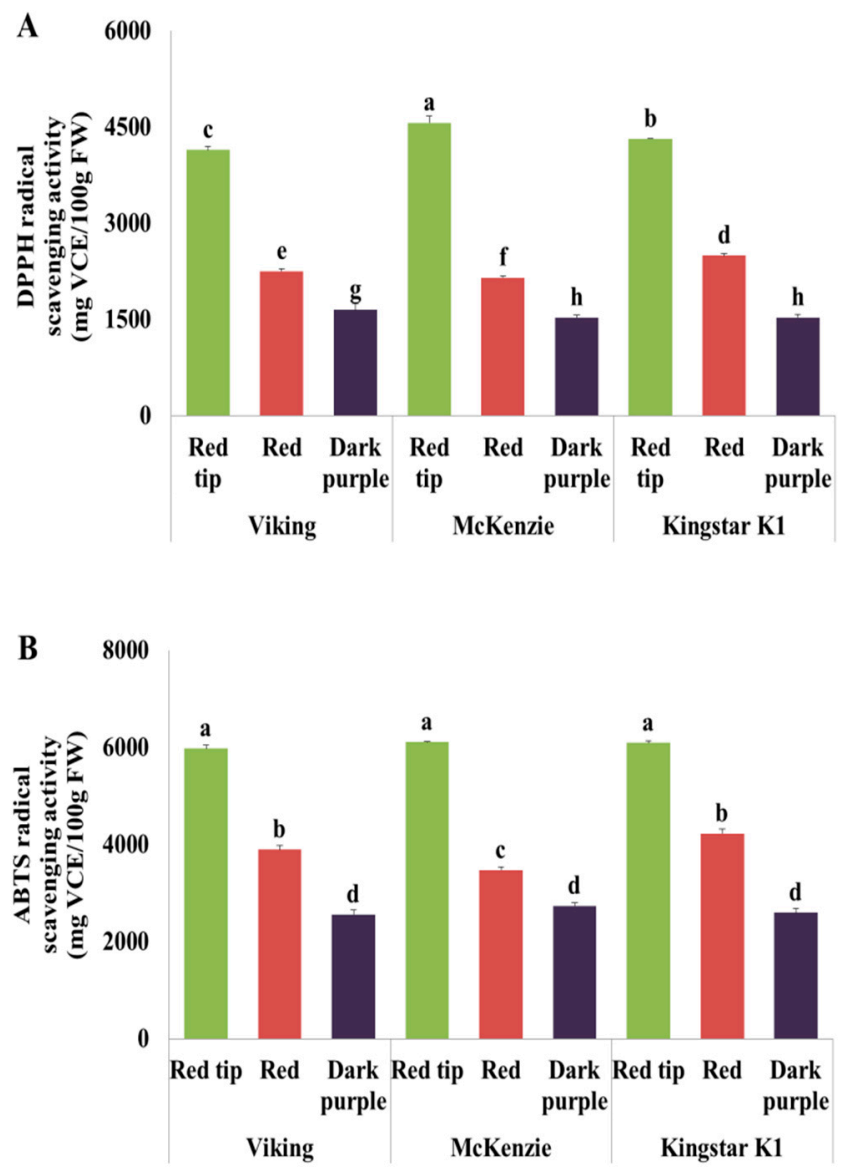

Figure 3. Antioxidant activities of Aronia melanocarpa fruits at different maturity stages: (A) DPPH radical scavenging; (B) ABTS radical scavenging. Vertical bars indicate standard deviation. Different letters are significant differences by Duncan's multiple range test $(p<0.05)$.

\subsection{Correlation between Physicochemical Quality, Antioxidant Substances and Antioxidant Activity in Aronia Fruit}

The correlation between antioxidant compound and antioxidant activity in aronia is shown in Table 5. The correlation between anthocyanin content and antioxidant compounds or activities were as follows: total flavonoid $(R=-0.753)$, total phenolics $(R=-0.705)$, DPPH radical scavenging activity $(R=-0.780)$, ABTS radical scavenging activity $(R=-0.839)$, catechol $(R=-0.674)$, and chlorogenic acid $(R=-0.655)$. These results indicate that the anthocyanin content of aronia increased during the ripening process, while the antioxidant compound, antioxidant activity and polyphenol content decreased during the ripening process. The correlation between total flavonoid and total phenolics was $R=0.991$ and the correlation between total flavonoid and antioxidant activities were also high: DPPH radical scavenging activity $R=0.997$ and ABTS radical scavenging activity $(R=0.979)$. Total phenolics and antioxidant activities were highly correlated and the correlation between total phenolics and catechol was $R=0.953$; and the correlation between total phenolics and chlorogenic acid was $R=0.940$. Wang and Lin [21] also found a negative correlation between the anthocyanin content of strawberry and ORAC (Oxygen radical absorbance capacity) value at green stage. Castrejón et al. [31] reported a strong correlation between antioxidant activity and total phenolic content in all blueberry cultivars. In addition, the remarkably higher total phenolic compound content and antioxidant activity in unripe fruits than in ripe fruits were due to a high concentration of hydroxycinnamic acid before ripening. Therefore, total flavonoid, total phenolics, and chlorogenic acid except total anthocyanin are excellent antioxidant compounds. 
Table 5. Pearson correlation among physicochemical qualities, antioxidant compounds, and activities of Aronia melanocarpa fruits.

\begin{tabular}{|c|c|c|c|c|c|c|c|c|c|c|c|c|c|c|c|c|c|c|}
\hline & $a^{*}$ & $\mathbf{b}^{*}$ & ssc & Firmness & $\begin{array}{c}\text { Titratable } \\
\text { Acidity }\end{array}$ & $\begin{array}{c}\text { Malic } \\
\text { Acid }\end{array}$ & $\mathrm{pH}$ & $\begin{array}{l}\text { Moisture } \\
\text { Content } \\
\end{array}$ & Fructose & Glucose & Sorbitol & $\begin{array}{c}\text { Total } \\
\text { Anthocyanin } \\
\end{array}$ & $\begin{array}{c}\text { Total } \\
\text { Flavonoids } \\
\end{array}$ & $\begin{array}{c}\text { Total } \\
\text { Phenolics }\end{array}$ & DPPH & ABTS & Catechol & $\begin{array}{c}\text { Chlorogenic } \\
\text { Acid }\end{array}$ \\
\hline $\mathrm{L}^{*}$ & -0.739 ** & $0.959 * *$ & $0.788^{* *}$ & $0.963 * *$ & -0.305 & -0.916 ** & & $-0.614^{* *}$ & $-0.885 * *$ & $-0.868 * *$ & $-0.798 * *$ & $-0.723^{* *}$ & $0.986^{* * *}$ & $0.986 * *$ & $0.981^{* *}$ & 0.967 ** & 0.935 ** & $0.925 * *$ \\
\hline$a^{*}$ & & -0.592 ** & $-0.792 * *$ & -0.578 ** & $0.456 *$ & $0.508^{* *}$ & $-0.384^{*}$ & $\begin{array}{c}0.068 \\
-073 * *\end{array}$ & $0.441 *$ & $0.406 *$ & $\begin{array}{l}0.335 \\
-084 * *\end{array}$ & $\begin{array}{l}0.124 \\
-083 * *\end{array}$ & -0.726 ** & -0.757 ** & $\begin{array}{l}-0.694 * * \\
0.098 * *\end{array}$ & -0.622 ** & $-0.708 * *$ & $\begin{array}{l}-0.706 \text { ** } \\
0.855 *\end{array}$ \\
\hline $\begin{array}{l}b^{*} \\
\text { SSC }\end{array}$ & & & & $\begin{array}{l}0.962^{* *} \\
0.715^{* *}\end{array}$ & $\begin{array}{l}-0.191 \\
-0.461 *\end{array}$ & $\begin{array}{l}-0.9550 * * \\
-0.699 * *\end{array}$ & $\begin{array}{c}-0.267 \\
0.370\end{array}$ & $\begin{array}{l}-0.723 * * \\
-0.292\end{array}$ & $\begin{array}{l}-0.936 * * \\
-0.66 \sigma^{* *}\end{array}$ & $\begin{array}{l}-0.926 * * \\
-0.56 * *\end{array}$ & $\begin{array}{l}-0.888^{* *} \\
-0.487 *\end{array}$ & $\begin{array}{l}-0.835^{* *} \\
-0.384\end{array}$ & $\begin{array}{l}0.953 * \\
0.805 * *\end{array}$ & $\begin{array}{l}0.927^{* *} \\
0.837 *\end{array}$ & $0.958 * *$ & $0.961 * *$ & $\begin{array}{l}0.897 * * \\
0.830 * *\end{array}$ & $0.855^{* *}$ \\
\hline $\begin{array}{l}\mathrm{SSC} \\
\text { Firmness }\end{array}$ & & & & & $\begin{array}{l}-0.4617^{*} \\
-0.192\end{array}$ & $\begin{array}{l}-0.6596^{* *} \\
-0.96 * *\end{array}$ & $\begin{array}{c}0.370 \\
-0.212\end{array}$ & $\begin{array}{l}-0.292 \\
-0.731 \text { * }\end{array}$ & $\begin{array}{l}-0.606 * * \\
-0.954 * *\end{array}$ & $\begin{array}{l}-0.576 * * \\
-0.943 * *\end{array}$ & $\begin{array}{l}-0.487 * \\
-0897^{*}\end{array}$ & $\begin{array}{l}-0.384^{*} \\
-0.857^{* *}\end{array}$ & $\begin{array}{l}0.8055^{*} \\
0.971^{*}\end{array}$ & $\begin{array}{l}0.837 * * * \\
0960 * *\end{array}$ & $0.790 * *$ & $\begin{array}{l}0.7311^{* *} \\
0.097 * *\end{array}$ & $0.830 * *$ & $0.820 * * *$ \\
\hline Titratable acidity & & & & & & & $\begin{array}{l}-0.412 * \\
-0.429 *\end{array}$ & $\begin{array}{r}-0.711 \\
0.080\end{array}$ & $\begin{array}{l}-0.9437 \\
0.037\end{array}$ & $\begin{array}{c}-0.933 \\
0.028\end{array}$ & $\begin{array}{l}-0.8997 \\
-0.093\end{array}$ & $\begin{array}{l}-0.807 \\
-0.038\end{array}$ & $\begin{array}{l}0.971 \ldots \\
-0.287\end{array}$ & -0.286 & $\begin{array}{l}0.980 \\
-0.243\end{array}$ & $\begin{array}{l}0.987 \\
-0.179\end{array}$ & $\begin{array}{l}0.906 \\
-0.282\end{array}$ & $\begin{array}{l}0.892 \\
-0.272\end{array}$ \\
\hline Malic acid & & & & & & & 0.276 & $0.791 * *$ & $0.941 *$ & $0.933 * *$ & $\begin{array}{l}-0.093 \\
0.891^{* *}\end{array}$ & $\begin{array}{l}-0.0938 \\
0.893 * *\end{array}$ & $\begin{array}{l}-0.088 * \\
-0.938 *\end{array}$ & $\begin{array}{l}-0.2000 * * \\
-0.909 *\end{array}$ & $\begin{array}{l}-0.9495 * * \\
-0.949\end{array}$ & $-0.971 * *$ & $\begin{array}{l}-0.202 \\
-0.869 * *\end{array}$ & $\begin{array}{l}-0.272 \\
-0.853 * *\end{array}$ \\
\hline $\mathrm{pH}$ & & & & & & & & 0.362 & $0.383 *$ & $0.399 *$ & $0.488 * *$ & $0.543 * *$ & -0.087 & -0.013 & -0.126 & -0.200 & 0.000 & 0.005 \\
\hline Moisture content & & & & & & & & & 0.748 ** & $0.768^{* *}$ & $0.733^{* *}$ & 0.885 ** & $-0.629 * *$ & $-0.580 * *$ & -0.642 ** & -0.711 ** & $-0.535 * *$ & $-0.515 * *$ \\
\hline Fructose & & & & & & & & & & $0.998 *$ & $0.981 * *$ & $0.911^{* *}$ & $-0.912 * *$ & $-0.883^{* *}$ & $-0.926 * *$ & -0.942 ** & $-0.857^{* *}$ & $-0.835^{* *}$ \\
\hline $\begin{array}{l}\text { llucoses } \\
\text { Sorbitol }\end{array}$ & & & & & & & & & & & & $0.920^{* *}$ & $-0.895^{* *}$ & $-0.862^{* *}$ & $-0.909 * *$ & $-0.929 * *$ & $-0.837^{* *}$ & $-0.813^{* *}$ \\
\hline $\begin{array}{l}\text { Sorbitiol } \\
\text { Total anthocyanin }\end{array}$ & & & & & & & & & & & & & $\begin{array}{l}-0.835 * * \\
-0.753 * z\end{array}$ & $\begin{array}{l}-0.794 \text { ** } \\
-0.705 * *\end{array}$ & $\begin{array}{l}-0.858 * * \\
-0.780^{* *}\end{array}$ & $\begin{array}{l}-0.877 \text { ** } \\
-0.089 * *\end{array}$ & $\begin{array}{l}-0.781 \text { ** } \\
-0.67 * *\end{array}$ & $\begin{array}{l}-0.758 \text { ** } \\
-0.655 \text { ** }\end{array}$ \\
\hline Total flavonoids & & & & & & & & & & & & & & $\begin{array}{l}-0.095 * * \\
0.991 * *\end{array}$ & $\begin{array}{l}-0.707 * * \\
0.997 *\end{array}$ & $0.979 * *$ & $0.961 *$ & 0.949 ** \\
\hline Total phenolics & & & & & & & & & & & & & & & 0.988 ** & 0.970 ** & $0.953^{* *}$ & 0.940 ** \\
\hline & & & & & & & & & & & & & & & & 0.987 ** & 0.954 *** & $0.943^{* *}$ \\
\hline $\begin{array}{l}\text { ABTS } \\
\text { Catechol }\end{array}$ & & & & & & & & & & & & & & & & & $0.917^{* *}$ & $\begin{array}{l}0.9033^{* *} \\
0.99 * *\end{array}$ \\
\hline
\end{tabular}

Pearson correlation $(R):{ }^{* *}$, significance at $p<0.01,{ }^{*}$, significance at $p<0.05$. DPPH: 2,2-diphenyl-1-picrylhydrazyl; ABTS: 2,2-azino-bis (3-ethylbenzothiazoline-6-sulfonic acid). L*: lightness; $a^{*}$ : redness; $b^{*}$ : yellowness. 


\section{Conclusions}

In summary, the physicochemical properties, changes in antioxidant compound composition, and antioxidant activity of three A. melanocarpa cultivars cultivated in Korea were analyzed in this study. It was found that the anthocyanin content of three $A$. melanocarpa cultivar fruits increased with maturation, but the contents of catechol, chlorogenic acid, total flavonoid, and total phenolics decreased as maturation progressed. In particular, catechol and chlorogenic acid were found to be higher in unripe fruits than in ripe fruits. Catechol, chlorogenic acid and total phenolics and antioxidant activity showed a very strong correlation. The major sugar components in aronia were identified as fructose, glucose, and sorbitol, and their concentrations increased as maturation progressed. Ripe fruits, which have been used as main raw materials of processed aronia food, had a higher anthocyanin content than unripe fruits, but polyphenol, antioxidant compound and antioxidant activity were higher in unripe fruits. However, there were no significant differences in physicochemical qualities, antioxidant compositions and activities among cultivars. This suggests that red tip aronia, unripe fruit, could be an effective source of health-beneficial antioxidant compounds as functional food ingredients. Thus, aronia fruits are expected to be useful in various fields other than processed food, and they may positively affect the farm market, thereby contributing to increasing farm household income.

Author Contributions: Conceptualization, Y.-J.K. and Y.S.; methodology, H.Y., Y.-J.K., and Y.S.; formal analysis, H.Y., Y.-J.K. and Y.S.; writing-original draft preparation, H.Y.; writing-review and editing, Y.-J.K. and Y.S.

Funding: This research received no external funding.

Conflicts of Interest: The authors declare no conflict of interest.

\section{References}

1. Rissanen, T.H.; Voutilainen, S.; Virtanen, J.K.; Venho, B.; Vanharanta, M.; Mursu, J.; Salonen, J.T. Low intake of fruits, and vegetables is associated with excess mortality in men: The Kuopio Ischaemic Heart Disease Risk Factor (KIHD) Study. J. Nutr. 2003, 133, 199-204. [CrossRef] [PubMed]

2. Tsuda, T. Dietary anthocyanin-rich plants: Biochemical basis and recent progress in health benefits studies. Mol. Nutr. Food Res. 2012, 56, 159-170. [CrossRef] [PubMed]

3. Wangensteen, H.; Bräunlich, M.; Nikolic, V.; Malterud, K.E.; Slimestad, R.; Barsett, H. Anthocyanins, proanthocyanidins and total phenolics in four cultivars of aronia: Antioxidant and enzyme inhibitory effects. J. Funct. Foods 2014, 7, 746-752. [CrossRef]

4. Kokotkiewicz, A.; Jaremicz, Z.; Luczkiewicz, M. Aronia plants: A review of traditional use, biological activities, and perspectives for modern medicine. J. Med. Food 2010, 13, 255-269. [CrossRef] [PubMed]

5. Snebergrova, J.; Cizkova, H.; Neradova, E.; Kapci, B.; Rajchl, A.; Voldrich, M. Variability of Characteristic Components of Aronia. Czech J. Food Sci. 2014, 32, 25-30. [CrossRef]

6. Denev, P.N.; Kratchanov, C.G.; Ciz, M.; Lojek, A.; Kratchanova, M.G. Bioavailability and antioxidant activity of black chokeberry (Aronia melanocarpa) polyphenols: In vitro and in vivo evidences and possible mechanisms of action: A review. Compr. Rev. Food Sci. Food Saf. 2012, 11, 471-489. [CrossRef]

7. Kim, Y.J.; Shin, Y. Antioxidant profile, antioxidant activity, and physicochemical characteristics of strawberries from different cultivars and harvest locations. J. Korean Soc. Appl. Biol. Chem. 2015, 58, 587-595. [CrossRef]

8. Meyers, K.J.; Watkins, C.B.; Pritts, M.P.; Liu, R.H. Antioxidant and antiproliferative activities of strawberries. J. Agric. Food Chem. 2003, 51, 6887-6892. [CrossRef]

9. Shin, Y. Correlation between antioxidant concentrations and activities of Yuja (Citrus junos Sieb ex Tanaka) and other citrus fruits. J. Agric. Food Chem. 2012, 21, 1477-1482. [CrossRef]

10. Chen, H.; Zuo, Y.; Deng, Y. Separation and determination of flavonoids and other phenolic compounds in cranberry juice by high-performance liquid chromatography. J. Chromatogr. A 2001, 913, 387-395. [CrossRef]

11. Brand-Williams, W.; Cuvelier, M.E.; Berset, C. Use of a free radical method to evaluate antioxidant activity. LWT-Food Sci. Technol. 1995, 28, 25-30. [CrossRef] 
12. Floegel, A.; Kim, D.O.; Chung, S.J.; Koo, S.I.; Chun, O.K. Comparison of ABTS/DPPH assays to measure antioxidant capacity in popular antioxidant-rich US foods. J. Food Compos. Anal. 2011, 24, 1043-1048. [CrossRef]

13. Kaack, K.; Kühn, B.F. Black chokeberry (Aronia melanocarpa) for manufacture of a food colorant. Tidsskr. Planteavl. 1992, 96, 183-196.

14. Taheri, R. Polyphenol Composition of Underutilized Aronia Fruits and Changes in Aronia Berry Polyphenol Content through Ripening. Master's Thesis, University of Connecticut, Storrs, CT, USA, 2013.

15. Jeppsson, N.; Johansson, R. Changes in fruits quality in black chokeberry (Aronia melanocarpa) during maturation. J. Hortic. Sci. Biotechnol. 2015, 75, 340-345. [CrossRef]

16. Tosun, I.; Ustun, N.S.; Tekguler, B. Physical and chemical changes during ripening of blackberry fruits. Sci. Agric. 2008, 65, 87-90. [CrossRef]

17. Tolić, M.T.; Krbavčić, I.P.; Vujević, P.; Milinović, B.; Jurčević, I.L.; Vahčić, N. Effects of weather conditions on phenolic content and antioxidant capacity in juice of chokeberries (Aronia melanocarpa L.). Pol. J. Food Nutr. Sci. 2017, 67, 67-74.

18. Cordenunsi, B.R.; Oliveira do Nascimento, J.R.; Genovese, M.I.; Lajolo, F.M. Influence of cultivar on quality parameters and chemical composition of strawberry fruits grown in Brazil. J. Agric. Food Chem. 2002, 50, 2581-2586. [CrossRef]

19. Mikulic-Petkovsek, M.; Schmitzer, V.; Slatnar, A.; Stampar, F.; Veberic, R. Composition of sugars, organic acids, and total phenolics in 25 wild or cultivated berry Species. J. Food Sci. 2012, 77, C1064-C1070. [CrossRef]

20. Siriwoharn, T.; Wrolstad, R.E.; Finn, C.E.; Pereira, C.B. Influence of cultivar, maturity, and sampling on blackberry (Rubus L. Hybrids) anthocyanins, polyphenolics, and antioxidant properties. J. Agric. Food Chem. 2004, 52, 8021-8030. [CrossRef]

21. Wang, S.Y.; Lin, H.S. Antioxidant activity in fruits and leaves of blackberry, raspberry, and strawberry varies with cultivar and developmental stage. J. Agric. Food Chem. 2000, 48, 140-146. [CrossRef]

22. Benvenuti, S.; Pellati, F.; Melegari, M.; Bertelli, D. Polyphenols, anthocyanins, ascorbic acid, and radical scavenging activity of Rubus, Ribes, and Aronia. J. Food Sci. 2004, 69, 164-169. [CrossRef]

23. Wang, S.Y.; Chen, C.T.; Wang, C.Y. The influence of light and maturity on fruits quality and flavonoid content of red raspberries. Food Chem. 2009, 112, 676-684. [CrossRef]

24. Acosta-Montoya, Ó.; Vaillant, F.; Cozzano, S.; Mertz, C.; Pérez, A.M.; Castro, M.V. Phenolic content and antioxidant capacity of tropical highland blackberry (Rubus adenotrichus Schltdl.) during three edible maturity stages. Food Chem. 2010, 119, 1497-1501. [CrossRef]

25. Jakobek, L.; Drenjančević, M.; Jukić, V.; Šeruga, M. Phenolic acids, flavonols, anthocyanins and antiradical activity of "Nero", "Viking", "Galicianka" and wild chokefruits. Sci. Hort. 2012, 147, 56-63. [CrossRef]

26. Sidor, A.; Gramza-Michałowska, A. Black Chokeberry Aronia Melanocarpa L.-A qualitative composition, phenolic profile and antioxidant potential. Molecules 2019, 24, 3710. [CrossRef]

27. Määttä-Riihinen, K.R.; Kamal-Eldin, A.; Mattila, P.H.; González-Paramás, A.M.; Törrönen, A.R. Distribution and contents of phenolic compounds in eighteen Scandinavian berry species. J. Agric. Food Chem. 2004, 52, 4477-4486. [CrossRef]

28. Zheng, W.; Wang, S.Y. Oxygen radical absorbing capacity of phenolics in blueberries, cranberries, chokeberries, and lingonberries. J. Agric. Food Chem. 2003, 51, 502-509. [CrossRef]

29. Amil-Ruiz, F.; Blanco-Portales, R.; Munoz-Blanco, J.; Caballero, J.L. The strawberry plant defense mechanism: A molecular review. Plant. Cell Physiol. 2011, 52, 1873-1903. [CrossRef]

30. Tarko, T.; Duda-Chodak, A.; Sroka, P.; Satora, P.; Michalik, J. Transformations of phenolic compounds in an in vitro model simulating the human alimentary tract. Food Technol. Biotechnol. 2009, 47, 456-463.

31. Castrejón, A.D.R.; Eichholz, I.; Rohn, S.; Kroh, L.W.; Huyskens-Keil, S. Phenolic profile and antioxidant activity of highbush blueberry (Vaccinium corymbosum L.) during fruits maturation and ripening. Food Chem. 2008, 109, 564-572.

(C) 2019 by the authors. Licensee MDPI, Basel, Switzerland. This article is an open access article distributed under the terms and conditions of the Creative Commons Attribution (CC BY) license (http://creativecommons.org/licenses/by/4.0/). 